\title{
Perceptions, practices and principles: Increasing awareness of 'night sky' in urban landscapes
}

\author{
Robin Mosseri \\ This study was conducted under the supervision of Professor Sean Kelly \\ Landscape Architecture, School of Environmental Design and Rural Development, Ontario Agricultural College \\ University of Guelph, Guelph, Ontario, Canada
}

\begin{abstract}
In urban centres the natural cycles of day and night have dramatically been altered by artificial lighting, creating a perpetually lit environment that is rarely considered an issue. Artificial lights are illuminating roadways, structures and public plazas with lighting schemes that are, in most cases, inefficient. Consequently, light pollution has greatly impacted the night by reflecting and refracting light into the atmosphere. Without appropriate consideration of integrating artificial lighting into the urban environment, our "night sky" experience is at risk due to poor approaches to public realm design. This study qualitatively explores light pollution analyzing it based on the environment, society and economy as a whole. A literature review, key informants, and case studies contribute to a greater understanding of light and create a framework to develop a design reference to light efficient urban development. This study examines the need for a shift in public perception, broadening an understanding of the effects of light pollution, and provides design considerations to aid urban night sky awareness, planning and design.
\end{abstract}

$\mathrm{L}$ ight has continually played a vital role for humanity; from the faint glow of fire pits to the present day electrical grids spanning nations, transitions in lighting have dramatically altered the night. Light pollution envelopes the night in populated cities and surrounding regions hindering or completely blocking views to the stars above. The importance of natural light cycles, or circadian rhythms, is only now being studied by researchers. Light pollution greatly affects the environment, is a massive waste economically and has negative impacts on society.

Light pollution has become a global issue that not only concerns the star enthusiast; the explorer, the poet, the mystic and the writer all owe some of their inspirations to the night sky. Humanity has dramatically altered the night and given little thought to what they have lost in the process. [1]

The saddest paradoxes of modern life: the fact that our developing technology can provide us with stunning images of the near and far universe, and at the same time blind our eyes to the stars above.

Human perception of artificial light is the main contributor to over lit environments since darkness, a necessary factor for health and well-being, is often misunderstood for danger and upheaval. There is a need to identify why humanity fears darkness and evaluate the necessity and significance of artificial lighting. By surveying an International Dark-sky Association (IDA) representative, a professional astronomer and the public, a greater understanding of how light plays a factor was deduced.

\section{STUDY GOALS AND OBJECTIVES}

Goal: To understand how the public perceives the night, define practices and principles that have resulted in poor artificial lighting schemes in the urban context and encourage future considerations to experience the 'night sky'.

The following objectives are intended to satisfy this goal:

1. To explore the body of knowledge on key lighting phenomenon related to environment, society and economy.

2. To examine what communities have done to maintain 'night sky' viewing.

3. To translate the identified strategies into a design reference to guide development of urban landscapes.

4. To apply these references to an urban study site to examine its potential as a "demonstration" of; a) an urban space that is light efficient; b) to raise public awareness towards the issue of light pollution.

\section{Exploratory Methods Overview}

This study began with a broad examination of the literature related to light pollution analyzing it based on the environment, society and economy. It highlights human interaction with light from a physical and psychological standpoint to further understand the inherent need for 
artificial light. The literature review allowed the author to narrow the focus of the study, and led to the development of a more defined research question: how to encourage public awareness to reconsider the 'night sky' as part of the urban landscape and develop an appropriate design solution?

While the review of literature provided insight on the study topic, the inherent complexity of the phenomena warranted further analysis. The case study method was used to identify and understand a broad range of approaches to sky-conscious lighting and urban design. Two case studies were identified to observe how an area can respond to light pollution.

Case study investigation methods included review of both published materials and websites. To help identify sources of information, informal discussions took place with key informants including a representative from the International Dark-sky Association (IDA) and a professional astronomer.

Case study site selection was based the following criteria: 1) selected sites should be located in either urban and/or desirable environments or those as having significant demands from a resident or visiting population; 2) promotion of the desire for stargazing must be present; 3) actions to protect the night skies' visibility must be in place; 4) the sites must be part of a role in educating citizens about night skies; and 5) the availability of published material on the case study sites was considered essential due to the available resources of the researcher.

Using an inductive approach with the area of study, data was gathered through the literature review, case studies, and conclusions drawn through analysis of patterns, themes and commonalities discovered in the review. This provided the reference for the application of considerations to a demonstration site. The information derived in this study was organized by themes, objectives, and commonalities (where applicable).

A demonstration site's selection was based on urban context, access and familiarity to the author. The demonstration site offered an application of considerations towards light efficient urban development and benefited from on-site observation, site analyses through aerial photography and mapping, and review of City of Toronto policy documents

\section{LITERATURE REVIEW}

Exploring the historical development, need for, and impacts of artificial light led to develop an understanding of the factors driving current practices of landscape design.

\section{The Need for Light}

Lighting has become a prevalent attribute of design for architectural and landscaping purposes. Building facades are dramatically lit to emphasize the unique aspects of structures, giving them prominence in the landscape. Spot lights highlight natural elements, creating points of interest. Commercial applications use lighting to identify and promote themselves [2] lighting is commonly used for the safety and security of vehicles and pedestrians alike [3]. The environment and astronomers often wish light was minimized for the health of ecosystems and their own professional interests. Although lighting is not desired by all, there is a need to strike a balance with conflicting desires [2].

\section{In Fear of Darkness}

Earth was once cast perpetually in half shadow, allowing the natural cycles of day and night to exist. All living things on Earth lived beneath a majestic canvas of glittering stars [4]. Ben Harder states: [4]

Then came fire, the candle, and the light bulb, gradually drawing back the curtain of darkness and giving us unprecedented control over our lives.

Since the dawn of religion, light has become synonymous with safety, comfort and beauty whereas darkness has been considered dangerous, fearful and ugly [2]. Public lighting schemes began in the 1450's in London, England when lanterns were first introduced to reduce crime and ensure public safety. Initially, business owners were ordered to hang lanterns outside storefronts to illuminate the passageways from November $1^{\text {st }}$ to February $2^{\text {nd }}$ with the exception of the full moon period. Paris followed suit as London then decreed mandatory lighting during the months of November, December and January. At 6 o'clock every evening, lanterns had to be placed on the first floor window sill to give satisfactory light for the roads. In the 1600's, France began suspending lanterns from cables spanning the roads to create a more prominent light system. This system was under direct authorities of the police, thus, directly associating public light with public safety [3].

As populations expanded, social parties began demanding more public lighting from their governed representatives. This led to the introduction of gas as a more efficient light source; in the early 1800's. In 1823, London's gas lighting system stretched over 215 miles containing 39,000 lamps. In the European city of Cologne, citizens had a fundamental belief that God appointed darkness and it should be respected. This view, however was not shared as gas illumination spread quickly across the country [3].

In the late 1800's, gas lighting still prevailed but a new form of lighting began to transpire, the electric lamp. In 1850 the New York police chief believed that "every electric light erected means a policeman removed" [3]. The first arc light system was introduced in Detroit with minimal success due to continual repairs and inefficient lighting from its dim glow which imitated twilight. Success of the electric lamp began once the incandescent bulb was invented, extinguishing gas lanterns permanently. [3]

The $19^{\text {th }}$ century led to the construction of mass electric lighting systems throughout developed nations [1]. Electric lighting quickly evolved from the incandescent bulb to high 
pressure sodium and metal halides lamps that had a whiter light, creating the ominous sky above [3]. Unfortunately, humans have evolved believing a brightly lit environment is a safe and comfortable space, overlooking the inherent need for darkness. Nathan Perkins, a professor at the University of Guelph, wisely notes that starry nights and city lights should remain mutually exclusive (2009)

\section{Light Pollution Defined}

Light pollution is caused by upward lighting that is reflected and refracted into the atmosphere and scattered by aerosols, hindering the view to the night sky. Lighting systems that aim light beyond the horizontal plane or direct beams at reflective surfaces will create upward lighting. Aerosols such as minerals, volcanic ash, salt crystals, pollen grains, bacteria spores and waste particles are scattered in the atmosphere. These particles are crucial in condensing atmospheric water and in turn, absorbing light that either hinders or completely blocks the view to the stars. The result is similar a cloudy night which forms a general haze over the sky that either deters or completely shields the stars above [1].

There are three types of light pollutants; glare, light trespass and sky glow. Glare is generally a site specific issue and is categorized as either blinding glare, disability glare or discomfort glare. All cases exhibit light that is inadvertently aimed in the wrong direction, causing visual discomfort or the inability to see depending on severity. Blinding glare, similarly experienced by staring at the Sun, is an intense light that does not allow stimulus response. Disability glare reduces visual performance and contrast as an example, oncoming headlights on a dark road. Lastly, discomfort glare minimally reduces visibility where light is a nuisance. Glare is considered a safety hazard in the realm of light pollution and is a common issue for drivers. [1]

Light trespass has a direct effect on people's lives by the implementation of insensitive lighting schemes. Light extends beyond property lines directly impacting adjacent land. This problem is localized and is often caused by artificial light directly shining into an unintended area, like a bedroom window. Complaints are commonly made to municipalities and, depending on the situation, may be mitigated by shielding the source. [3]

Sky glow has a greater impact at a larger scale and is caused by upward lighting that diffuses back towards Earth [2]. It is caused by two main contributors; natural and human induced illumination. Natural sky glow is light from elements such as the Sun, Moon, planets and stars that scatter dust particles, water vapour and aerosols. These airborne particles attenuate atmospheric water and inadvertently absorb light which is then viewed as a luminous glow from Earth [3]. Human induced sky glow is a much brighter illumination as light is carelessly or deliberately projected and reflected back into the atmosphere [1]. Sky glow reduces luminance contrast, making it hard to distinguish night features as a result, an ominous glow [1].
Light pollution is primarily caused by poor lighting design and practices that do not employ strategies to ameliorate reflective and upward lighting. Sky glow has the greatest overall impact as glare and light trespass affect individuals first hand although these tend to be more commonly addressed through design and practice.

\section{The Impacts of Poor Design, Practices and Policy}

Lighting beautifies city and townscapes by highlighting architecture, roadways and public plazas. The issue is not to address the removal of light but to improve lighting to minimize upward and reflected luminance. In addition, there is a need to re-evaluate the incidence of light in reflected surfaces by considering road surfaces, landscape and buildings [2].

A further obstacle is that light pollution is rarely considered a serious concern due to the lack of awareness by the public, authorities and government. Once lumens became low in cost and efficient to install, the natural darkness was doomed to last [2]. The following section outlines the detrimental impacts of light pollution on the environment, economy and society.

\section{Environmental Impact of Excessive Lighting}

According to Bob Gent, of the IDA, United States alone contributes over 38 million tons of carbon dioxide emissions a year in excess lighting. These inefficiencies are extremely concerning in a world that is facing a serious climate change crisis. Global climate change has a direct impact on sea level rise, temperature increase and extreme weather patterns dramatically changing the present and future conditions on Earth. Light pollution, a single product of carbon emissions, has a direct effect on all species reliant on the natural rhythms of day and night. [1]

Specifically, artificial light affects the feeding, breeding and migration patterns of all species [1]. Recent studies identify critical species being affected; these include birds, sea turtles, frogs and insects.

More specifically, night lighting has had the greatest impact on bird species. The organization, Fatal Light Awareness Program (FLAP) [5], has identified that there is a greater bird mortality rate by light attraction then that of a catastrophic oil spill. The lethal combination of glass, the attraction to light, disorientation and weather conditions can injure or kill hundreds and even thousands of birds in a single night. Toronto has reported over 140 different species of birds colliding with buildings in a year during nightfall. FLAP estimates that up to 100 million birds have died in North America in the last year alone, Figure 1 gives an astonishing illustration. Artificial light has also disoriented nocturnal birds that rely on the moon and stars for navigation purposes for their migration bi-annually [4] [5].

Sea turtles have also been negatively influenced by light pollution. They are predisposed to nesting on dark beaches which limits available breeding areas. The hatchlings gravitate to bright areas believing it to be the sea 


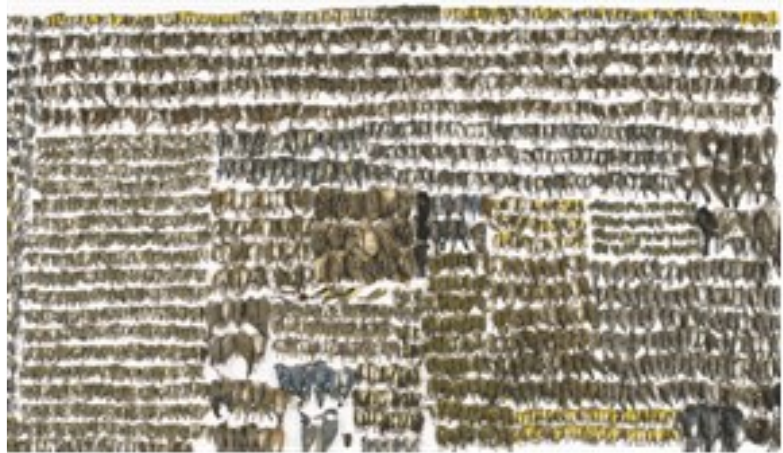

Figure 1. Species of Birds killed in one Year in North America: The sad reminder of the impacts of birds colliding with buildings at Night [6]

horizon, disorienting them. In Florida, hatchlings losses range in the hundreds of thousands every year, as the turtles fail to reach their ocean habitat. [7].

Frogs and toads closely associated with brightly lit areas also suffer because their nocturnal night levels or natural darkness level are a million times brighter than their normal habitat. This illumination directly affects every aspect of their behaviour such as their breeding choruses. [7].

The implications of light pollution towards insects are severe. These small creatures have always been drawn to light and are easy targets for foraging predators such as bats. Fireflies cannot reproduce near incandescent lights since it mimics their spectrum of light. Moths tend to lose their defensive abilities near artificial light making them extremely vulnerable. In a year, billions of nocturnal insects are killed near artificial lights. [4] Although insects are a seemingly small organism affected, the change in foraging behaviour can dramatically alter many systems down the food web and in future generations of predators.

Photosynthetic organisms have also been impacted by light pollution. Particularly, light induces physiological activities that stimulate flowering, reproduction, and resting periods of plants. Only vegetation in direct relation to light is affected. Seasonal rhythms are altered due to the change in day lengths. Pigments in the leaves have also been noted to change. Although not as severe an impact as seen in the examples above, these changes do alter the natural cycles of plants. [2]

Every living organism in the urban environment must adapt to perpetual artificial light in populated cities and vast surrounds. Although only a few studies have directly linked the detrimental aspects of light pollution to various species, all species must alter their way of living to adapt or perish due to the impacts on their feeding, breeding and migration patterns.

\section{Economic Impact of Excessive Lighting}

Proper lighting schemes are necessary to reduce energy consumption and incident lighting. The United States invested \$10.4 billion dollars in inefficient lighting in the year, 2009[8].Wasteful and ill-conceived lighting plans have little merit when easily remedied with proper wattages, lighting fixtures and trajectories.

One must investigate the energy consumption of an entire nation to fully understand how energy is distributed throughout public lighting. Household energy in most industrialized countries accounts for approximately $10 \%$ of a nation's total energy per annum. Road transport, heating and industries comprise the remainder of total energy. Public lighting is only a small percentage of total household energy usually totaling less than $1 \%$. Although a seemingly small percentage, it still compounds to create a surprisingly large amount of energy consumption. [2]

Practicing appropriate energy saving techniques, such as proper wattage, reducing glare and promoting light fixtures that direct light downward, will help reduce energy consumption and minimize greenhouse gas emissions [9]. Although suitable light fixtures and lamp fittings generally cost more, they are sustainable and will benefit future generations.

\section{Social Impact of Excessive Lighting}

Humanity has tampered with the circadian rhythms in nature which have inadvertently caused detrimental impacts on human health [1]. Artificial lighting has altered the natural day and night cycles that have been necessary for proper biological rhythms. Humans rely on these rhythms for sleep patterns, vigilance, tiredness and fatigue [2]. The hormone melatonin, secreted from the pineal gland, is responsible for the sleeping and waking regularities and brain activities, [10]. Studies now suggest that perpetual light suppresses melatonin causing hormone irregularities, and even some forms of cancer [4].

Normal melatonin production occurs during dark nights between 2 am and 4 am and as bright daylight unfolds the clock is 'reset' creating a 24 hour cycle. The system is highly sensitive to light to stimulate normal secretions of melatonin. The melatonin hormone has sleep-inducing properties that help regulate a balanced physiological state; it is also is a powerful antioxidant. Furthermore, blue wavelength lighting is the most disruptive to the natural frequency of melatonin production. Blue light seen in LED's is particularly problematic and can affect multiple functions such as body temperature, hormone release from the pituitary gland and sleep patterns.

Shift workers best exemplify an irregular melatonin distribution. Recent studies have shown a greater percentage of breast cancer occurrences for shift workers at a rate of $36 \%$ to $60 \%$. Paradoxically this number is three to five times higher in contrast to developing countries that are not as bombarded with artificial light. Approximately, 50\% of all breast cancer causes are unknown, it can be suggested that light may have played a significant role in those cases. Colorectal cancers have also had a higher incidence for shift workers where $35 \%$ have been affected. [10] 
Although there is no definite proof linking artificial light to cancer, there are significant factors suggesting that disturbing circadian rhythms may be a factor. There is evidence suggesting that shift workers live five to six year less than the average working person, so perhaps a dark night sleep plays a larger role than one assumes [2]. Artificial light should be recognized for its harmful effects of disrupting the natural day-night rhythms that contribute to hormone irregularities, sleep disorders and some forms of cancer.

\section{Public Perception of Light: The Safety Debate}

The invention of artificial light has greatly safeguarded and enhanced the nighttime environment; is this conclusive? [1] There have been numerous debates concerning the correlation between public lighting and crime since the very foundation of artificial light.

There are popular beliefs that the improved visibility at night allows for easier identification and apprehension of criminals. Light is usually considered a deterrent, warding off such criminal activities. Functionally, light increases visual performance, optimizing visual speed and increasing the ability to make judgements and react to different situations [3]. Light also helps enable people to recognize threatening situations by identifying body language and facial expressions- giving an opportunity to escape [3]. However, improved public lighting enhances the visibility of both the criminal and law abiding citizen; so who does it favour? Light can become a courtesy for criminals allowing them to easily reach and escape their targets [1]. In addition to visibility, there is a belief that if criminal situations takes place, spectators could intervene. There is troubling evidence suggesting that in light of a serious situation, civilians rarely intervene in actions that may cause risk to themselves [1]. Others believe, if a criminal can evaluate the risk and has already been committed to an act, light will neither provoke nor deter their actions.

Although the act of sight seems to favour both the criminal and the law-abiding citizen, the perception of safety is affected by light. There is firm evidence deeming that society feels safer and less fearful in a well-lit environment [3]. A case study was devised, evaluating campus lighting by Fisher and Nasar (1992) which outlined where citizens felt most at risk. It revealed that students felt insecure in areas where there were places to hide, had restricted views or areas with little room for escape. The study concluded that proper lighting schemes would diminish places to hide and open view sheds but did not assess the inadvertent aid of ameliorating lighting for criminal activities [3]. Nevertheless, the sociological impacts of light always suggest that people have a reduced fear in a well-lit environment [11]. Another question then arises, what defines a well-lit environment?

When light is introduced for security purposes it is often at too high a wattage necessary for a 'safe' environment. Security lighting is commonly between 300500 Watts although the IES standards recommend 150 Watts as more than adequate [1]. These lighting situations create a more interrogative setting that can unintentionally blind citizens. For example, security lamps mounted in a parking lot can involuntarily create blind spots beyond the light fixture, allowing criminals to easily view and apprehend their targets since they are on display [3]. The impact of relighting can also be influenced by the scale of improvement. The introduction of light into previously dark areas may have a greater effect than the incremental amelioration of lighting. [11]. Consequently, the quality of light can only be developed on an individual scale, and alas, may or may not have an effect on crime.

Humanity has adapted to brightly lit environment, believing that darkness leaves us blind and helpless. The human eye, however, can adjust to low level night time illumination in unpredictably dim conditions when given the chance. A hormone called rhodopsin, otherwise known as 'visual purple,' stimulates the cylindrical rod cells in the retina at low light conditions. The retina can usually adapt to low light within a few minutes which is why driving a dark stretch of highway is not tiring on your eyes for a long period of time. [1]

The understanding that light is needed to ease social apprehensions yet recognize that there is no direct correlation with crime will be challenging to accept. Perhaps focusing on proper lighting conditions that illuminate an area with limited upward and reflected light would best solve light pollution.

\section{Designing for Night Skies}

When walking around a city neighbourhood, people need to realize the amount of incident lighting glaring upon them, empty parking lots brilliantly lit and commercial premises seemingly still open after hours [12]. There is a common misconception in lighting that more light is better, however, the best solution is improved lighting quality as previously mentioned. Light pollution can be easily remedied by establishing awareness of the issue, installation of proper lighting schemes and considering incident lighting. Since light pollution is a global issue an international agreement should be met to develop a universal lighting standard that properly mitigates upwards and reflected light [1]. Currently, there are many 'islands of good practice' where local communities have established the need to protect the night sky but this small scale action should expand due to the detrimental effects light pollution has on the economy, environment and society. [1]

There is a need to extinguish all lighting that emits beams above the horizontal level for roadside and ground lighting. Security and spot lighting should be at the proper wattage and incidence to reduce glare and reflective properties. Motion sensor lighting also helps minimize overall usage. All decorative fixtures should be at a low lumen output to minimize upward lighting. Although aesthetically pleasing, removing the uplighting on buildings will reduce sky glow since they are one of the prime contributing factors. The IESNA has devised standards for 
full cut off fixtures that direct light downward and minimize spill light. [9]

The IDA provides an Outdoor Lighting Code Handbook that demonstrates acceptable lighting practices and provides a vast index of lighting solutions for industrial, landscaping and parking situations. The Commission Internationale de l'Eclairage (CIE) has developed zoning classifications to determine areas that are sensitive to light and areas where light has a lesser impact. Four specific zones were categorized from E1, areas of natural dark landscapes that need protection to $\mathrm{E} 4$, urban areas with considerable night time activities (see Table 1: CIE Zoning for Sensitivity [13]). The system helps reduce light pollution in zones deemed sensitive but does not consider the implications of light in high district areas.

To achieve proper lighting quality, light must be strategically placed where needed. The Royal Astronomical Society of Canada (RASC) has developed a light abatement program that strives to promote dark skies. The program focuses on public awareness, civic promotion, municipal guidelines and light pollution bylaws. Light pollution is a nationwide problem but is only addressed through the jurisdiction of local municipalities. Therefore, volunteers must approach professionals and government agencies to argue the need for darkness. By educating on the basis of environmental, social and economic impacts of light pollution, these volunteers strive to promote efficient lighting techniques. [14]

Designers should consult the Outdoor Lighting Code Handbook [8] to consider minimizing all unnecessary and inefficient light practices. It is still possible to create an aesthetic night landscape that does not hinder the view to the skies above. The implementation of full cut-off luminaires and the consideration of incident lighting will help minimize overall lighting issues. The night sky should be considered one of the greatest aspects in all designs for it is a palette of inspiration and wonder that has marvelled humanity since life began.

Table 1. CIE Zoning for light sensitivity [13

\begin{tabular}{|c|c|}
\hline Environmental zones & Examples sub-rones \\
\hline E1 & Areas with intrinsically dark landscapes \\
\hline Ela & - nature peserves \\
\hline E1b & - national parks \\
\hline E1e & - areas of outstanding natural beauty, peotected landscapes \\
\hline E2 & $\begin{array}{l}\text { Areas of low district brightness: rural agricultural areas, village } \\
\text { residential areas }\end{array}$ \\
\hline $\mathbf{E 3}$ & Areas of middle district brightness \\
\hline E3a & - sub-urbas residential areas \\
\hline $\mathbf{E 3 b}$ & - urban residential areas \\
\hline E4 & Areas of high district brightness \\
\hline E4a & $\begin{array}{l}\text { - urban areas having mixed resideatial, industrial and commercial } \\
\text { land use with considerable nigattime activity. }\end{array}$ \\
\hline EAb & $\begin{array}{l}\text { - city and metropolitan areas having mixed recreational and } \\
\text { conmercial land ase with high nighttime activity }\end{array}$ \\
\hline
\end{tabular}

\section{CASE STUdies}

In reaction to how light pollution affects communities, two case studies were identified to observe how an area can respond to this issue. The research helps reveal the outcomes of efficient lighting systems and acts as a precedent for overlit skies.

Flagstaff, Arizona is one of the United States of America's leading astronomical research bases and is no wonder also a frontrunner in the protection of the night. Torrance Barrens, Ontario is the first dark-sky preserve of its kind and provides an excellent opportunity for stargazers to visit and enjoy the northern hemisphere. Both locations have strict policies and guidelines set by the neighbouring communities to protect the valued night.

\section{Flagstaff, Arizona, United States:}

In 1894, the astronomer Percival Lowell entered the quiet town of Flagstaff, Arizona with a Clark telescope choosing the location based on its high elevation and clear dry skies [15]. The town quickly became a leading astronomical research centre with the development of the Lowell Observatory, United States Naval Observatory of Flagstaff and the National Undergraduate Research Observatory. In fact, in 1930 Flagstaff astronomers were the first to discover Pluto [15]. The success of this development rested solely on the stars above, thus, proper lighting schemes are crucial to protect them. This location also hosts thousands of amateur astronomers and visitors alike who seek refuge from bright city lights. [16]

As a result, Flagstaff, Arizona became the first IDA city. The small population of 60,000 residents has lived with a great respect for the night sky. The first ordinance declared by the Flagstaff City Council 1958, restricted the use of search lights, floodlights and harmful upward lighting. In 1989 , the county created innovative lighting codes to combat the rise in population. The code outlined the necessity to prohibit light trespass, glare and sky glow in this light sensitive area. Legislation approved restrictions on all outdoor lighting elements ensuring the highest quality lighting codes. The Flagstaff IDA also created a campaign named the 'FDSC Million Lumens Campaign' to reduce lumens and replace outdated fixtures by providing a generous incentive to local businesses. The replacements of high pressure sodium and mercury vapour lamps with low pressure sodium lamps that are fully shielded was mandated to minimize light pollution [15]. Flagstaff, Arizona is an excellent example of a light savvy community that has innovative techniques and the motivation to preserve the night sky. Although most cities do not have the same astronomical presence, the techniques can easily promote dark skies in all willing communities. [16] 


\section{Torrance Barrens, Ontario, Canada:}

Torrance Barrens is a smaller scale example that demonstrates the effectiveness of a Canadian Dark-sky Reserve. The reserve was the first of its kind, established in 1990 to address and mitigate the growing intrusion of light pollution on astronomical events. The director of the Natural Heritage Project, Peter Goering, in partnership with the Ministry of Natural Resources and the Ontario government, helped to designate the zone free of urban light pollution near many local communities in the Muskokas. The Township of Muskoka Lakes passed a resolution that all artificial lighting must be directed downwards aiding in the recovery of the night sky surrounding Torrance Barrens Dark-sky Reserve. [17]

Torrance Barrens is a 1900 hectare dark refuge of intrinsically beautiful environment with rock outcrops, rare plants, wildlife and many recreational opportunities. The true spectacle, however, is the night scene. The area is situated on Precambrian bedrock that is categorized by low ridges and separated by wetlands. The location was also chosen based on the relatively open expanse in tree canopy, with views to the horizon, solid granite surfaces perfect for the telescope and night photography as well as accessibility to major cities such as Toronto and Hamilton approximately 2-3 hours away [18]. The inspirational vistas proudly feature the Milky Way, occasional northern lights and many other constellations that are never observed in the urban setting. The Dark-Sky Reserve helps reconnect citizens to the natural wonders of the skies above and is an avid example that can be used to educate and promote dark skies in many communities.

\section{CONSIDERATIONS FOR DESIGN APPLICATION}

From the literature and the case studies reviewed, five key considerations for landscape architecture and urban design related to lighting and night skies were identified:

1. Protection of the night sky has contrasted undoubtedly with society;

2. Society feels safer in a lit environment;

3. Focus should be on improvement of lighting quality to reduce the impacts of light pollution rather than the removal of artificial light;

4. Issues of light trespass and light pollution should be considered as a forefront to design;

5. Education is the best offence against light pollution is making the issue openly known and creates interest in the skies above.

Further, references for design applications were developed providing an opportunity to both explore urban site lighting efficiency and the potential for raising public awareness towards the night sky and light pollution.

\section{A Study Site Application}

The background of the selected study site includes a small open parkette bordered by alleyways and is located on
Queen Street, a vibrant and trendy area in the heart of Toronto. The location is nearby the Royal Ontario Museum and the Art Gallery of Ontario, two very popular tourist destinations for arts, science and culture that can also connect to the site. The Royal Ontario Museum also once hosted a large planetarium that explored the history and experience of astronomy, but due to a lack of interest and funding, it was sold to the University of Toronto in 2009 and is planned to be demolished. There is a smaller scaled astronomy oriented venue left on site further proving the lack of interest in astronomy today. This site is adjacent to several eateries including: Everest, East and Ben \& Jerry's Restaurant; they cater to evening and daytime uses; the two alleyway 'pocket' parks are used solely for restaurant clientele. The park on Renfrew Drive, named St. Patrick's Market was also included as part of the study site since it was underutilized in the urban environment. (See Figure 2 for an illustrated version of the site context)

\section{Opportunities and Challenges}

Key opportunities and challenges for the site application are a result of observations recorded during site visits, and conclusions drawn through review of relevant documents. Opportunities included the availability of solar power collection, retrofitting an existing area that is otherwise unused and creating a light pollution focused design in an urban context. The major challenges included how to redesign the existing site with consideration to the adjacent uses and materials that may inadvertently affect the design and establish a safe and effective light pollution design.

The overall concept would address a manner to create efficient lighting scheme with a sustainable power source generated from the photovoltaic panels proposed on the

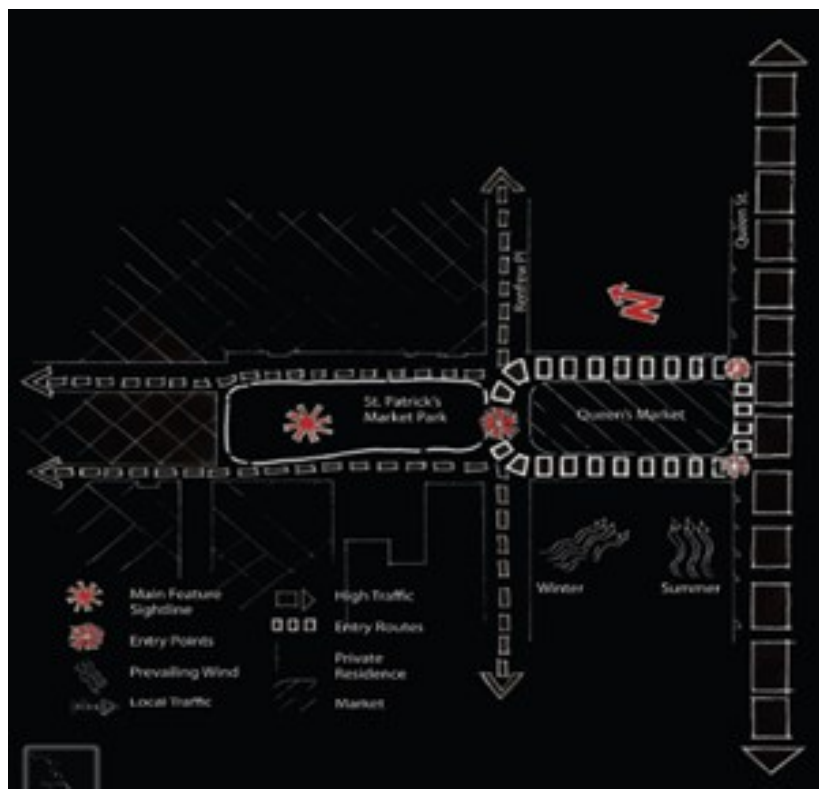

Figure 2. Site Context Plan 
Queen's Market. Offering an understanding of the significant contrast between a sky affected by light pollution and areas where light is nonexistent will be difficult on such an urban site - other means will need to be employed.

\section{Key Design Programmatic Ideas}

Specific programmatic elements were guided by objectives related to raising public awareness, engaging site visitors and demonstrating 'best practices' in site lighting design. These have been categorized into four main themes:

1. Safety \& Security - one of the greatest challenges for the design was to ensure a feeling of safety and security within a dark sky environment. Thus, the design does not propose the elimination of lighting, rather a more efficient layout; minimizing the effects of light on the vertical plane.

2. Light Pollution Awareness Devices - the Bird Memoriam Panels, and Contrast/Void feature:

The Bird Memoriam Panels were a series of glass panels with a silhouette of a bird; representing many species of birds that have perished in Toronto. Approximately 140 different species of birds and over 100 million birds have died in North America in a year alone [6]. The window-pane screen illustrated the devastating effects that light pollution has on migratory birds. (See Figure 3: The Bird Memoriam Panels)

Contrast/Void Installation demonstrates the difference between a sky affected by light pollution and areas where light is nonexistent. This installation unveils a clear night versus an urban night; the voids or holes help identify the contrast and raise awareness to the impacts of artificial light. (See Figure 3: The Bird Memoriam Panels and Contrast/ Void Feature)

3. Minimal Refraction Techniques - All lighting fixtures proposed in the design are "full cut-off" (no light exceeds the horizon or 90 degree angle). All lighting is proposed to be high efficient LED's, with wattage ranges in conformance to IDA standards [19]. Lighting was also carefully placed on nonreflective surfaces such as planting beds and asphalt to minimize any refracted light.

4. Purposeful Public Art - exciting the general public to look up and beyond the horizontal plane utilized an element called, the Branches of our Northern Hemisphere; a large tree form that acts as a symbolic connection between our Earth and the Universe. The tree itself is a delicate depiction of the constellations about us, reminding the public of the beauty above. Seating also guides the viewers' gaze upwards with lounge chairs and rolling berms to continue drawing the attention to the vertical plane. (See Figure 4: the Branches of our Northern Hemisphere).

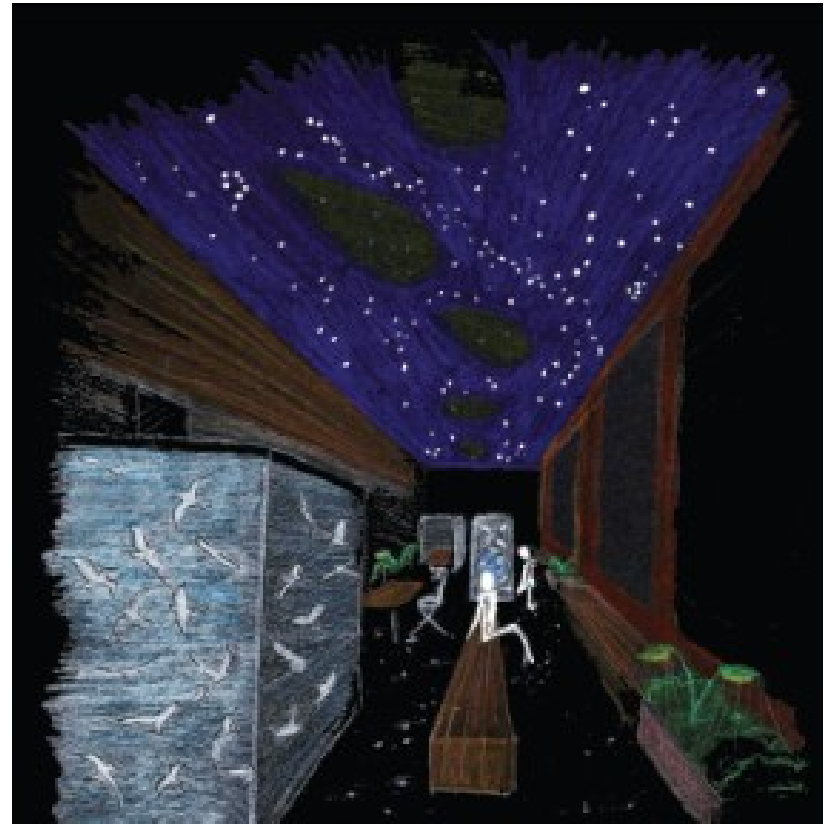

Figure 3. The Bird Memoriam Panels and Contrast/Void Feature

This demonstration, one of many possible solutions, considers the diversity of the issue and created elements that would not only educate the viewer, but excite them. It proposes a redevelopment of the site prioritizing consideration of the night sky in an urban context. The demonstration plan aspires to act as a precedent for future site lighting designs with one major goal, to raise awareness of the inspiration above and mitigate light pollution.

\section{Relevance of the Considerations to Practice}

It was not the intention of this study to establish a single blueprint for addressing social stigmas, energy consumption and light pollution for the design of urban landscapes, as each one is unique and may require a different type of intervention, but rather to provide a series of considerations to guide the design outcome. Bringing together the general body of knowledge of lighting phenomenon, lighting design, and night sky preservation, these considerations could be useful in a number of different contexts. First, increasing

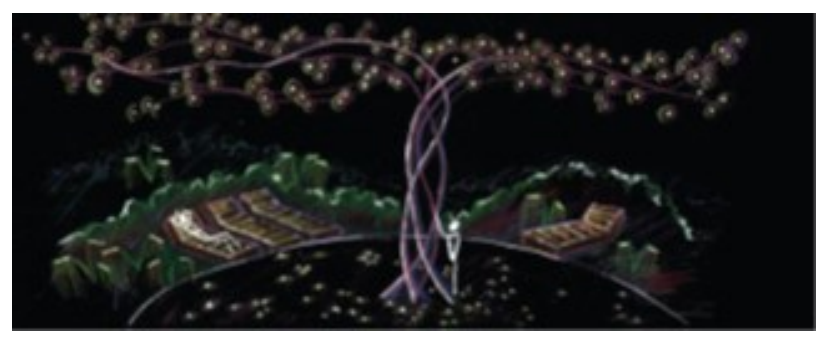

Figure 4. The Branches of our Northern Hemisphere 
awareness may present opportunities to those involved with planning, design and management of urban space, new and existing sites, night sky conservation, and may guide policy towards "night sky" preservation.

Second, these considerations could be evolved into an evaluation tool to assess site plan compliance to night sky preservation policies or to review site lighting design proposals in their conceptual stage.

\section{CONCLUSION}

The primary goal of this study was to understand how the public perceives the night, define practices and principles that have resulted in poor artificial lighting schemes in the urban context and encourage future considerations to experience the 'night sky'. Issues related to light pollution, night sky perception and awareness, and conservation techniques were compiled into considerations that could be used to guide the design of urban landscapes. Light has become a 24 hour phenomenon and continues to play an essential role in society, providing a sense of 'security' and aesthetics. There is a need to reevaluate the importance of circadian rhythms for all species as a whole to fully comprehend the impacts of artificial lighting at a broader scale. The inefficiencies of public lighting have contributed to millions of tonnes of global greenhouse gas emissions annually. The major challenge of light pollution is combating the public perception of light. While light is known to enhance an individual's sense of security, the public needs to be aware that a brightly lit environment is not always advantageous and mitigation for quality over quantity is required for night lighting. Planning and design professionals, policy makers, municipal officials, and citizens have a responsibility to ensure appropriate use of light. Many opportunities and considerations exist to aid in the preservation of the night sky. A continued disregard for these will further diminish the night sky experience most notably in our urban environments.

\section{REFERENCES}

1. Mizon, B. (2002). Light pollution. Springer Verlag.

2. Schreuder, D., \& Narisada , K. (2004). Light pollution handbook. The Netherlands : Kluwer Academic Pub.
3. Boyce, P. (2003). Human factors in lighting second edition. New York : Taylor \& Francis . CIE, . (1997). Zoning by-laws for light reduction. (http://www.cie.co.at/index.php/Publications/Technical+Repo rts+and+Guides)

4. Harder, B. (2008, March 24). Turning out the lights. News and World Report, 144(9)

5. FLAP, . (2009). Fatal light awareness program. (http://www.flap.org/flap home.htmCIE)

6. FLAP, (2009). Fatal light awareness program. (http://www.flap.org/flap_home. htmCIE)

7. Klinkenborg, , \& Verlyn, . (2008, November). Our Vanishing night . National Geographic, 214(5).

8. (2009). International dark-sky association . (http://www.darksky.org/)

9. Ryan, K. ASLA, Monsum, M. (1996). Outdoor Lighting Manual For Vermont Municipalities. Chittenden County Regional Planning Commission Vermont: Queen City Printers Inc.

10. Pauley, S. (2003). Lighting for the human circadian clock: recent research indicates that lighting has become a public health issue. Medical Hypothesis, 63, 588-597.

11. Atkins, S, Husain, S, \& Storey, A. (1991). The Influence of street lighting on crime and fear or crime. London : Crown .

12. Gallina, C, \& Mandyck, J. (2009). Light done right. Library Journal,

(http://www.libraryjournal.com/article/CA6696205.html?indu stryid $=47090$ )

13. CIE 150 (2003). from Schreuder, D., \& Narisada , K. (2004). Light pollution handbook. Pg 141-142 The Netherlands : Kluwer Academic Pub.

14. (2009). Light pollution abatement program. (http://www.rasc.ca/light/)

15. Friederici, P. (2001). Stargazers defend darkness in Arizona. High Country News, (216), (http://www.hen.org/issues/216/10890)

16. Flagstaff Dark Skies Coalition, . (2007-2009). Flagstaff's dark skies coalition. (http://www.flagstaffdarkskies.org/index.htm)

17. Maddock, B, Kuntz, K, \& Goulbourne, P. (2009). Muskoka heritage foundation natural heritage program. ( http://www.muskokaheritage.org/natural/torrancebarrens.asp

18. Silver, M. (2009). Torrance barrens dark sky reserve rasc designation dark sky preserve (http://www.rasc.ca/lpa/torrancebarrens.shtml)

19. International Dark-sky Association, . (2002, September). Outdoor lighting code handbook. (http://www.darkskysociety.org/handouts/idacodehandbook.p df) 